\title{
The Association between Complete Denture Wearing and Denture Quality with Oral Health Related Quality Of Life in an Elderly Gujarati Population
}

\author{
Dr. Rupal J. Shah ${ }^{1}$, Dr. Anandmayee Chaturvedi ${ }^{2}$, Dr. Farheen Malek ${ }^{3}$, Dr. \\ Hardik Prajapati ${ }^{4}$, \\ ${ }^{\text {I }}$ H.O.D. \& Professor, Department of prosthodontics, Government dental college \& hospital,Ahmedabad,India) \\ ${ }^{2,3,4}$ (Postgraduate student,Department of prosthodontics, Government dental college \& hospital, Ahmedabad, \\ India)
}

\begin{abstract}
Aim: This study aims to determine whether complete dentures improve the quality of life of an edentulous patient, and will also assess the roles of socioeconomic and demographic factors. The study will further assess the association between psychosocial, socioeconomic and demographic factors and patients' level of denture satisfaction.Material \& Method : A final sample of 630 patients was then included in the study. Eighty-one percent ( $n=510)$ of the sample was female. The age ranged from 34 years to 80 years old with a mean age of 58 years.Result: Generally, all the patients were satisfied with the maxillary denture received during their treatment. A higher rate of dissatisfaction was recorded for the mandibular denture (36\%) than the maxillary denture (10\%). More than two thirds (68\%) of the sample experienced great difficulty eating with their previous dentures and only $42 \%$ experienced pain in their mouth in the last month. Patients recorded higher impacts related to functional limitations. This could be due to ill-fitting dentures, inadequate retention and the resulting discomfort experienced by edentulous patients. Conclusion: The findings of this study could also serve as motivation for a more vigorous national plan with regards to oral health. The high prevalence of edentulism clearly suggests that the levels of tooth loss are not decreasing. The results of this study and future research could be used to motivate for more appropriate resource allocation.
\end{abstract}

Keywords: Complete denture and quality of life, Oral health related quality of life, Quality of life

\section{Introduction}

The World Health Organisation (WHO) defines health as "a state of complete physical, mental and social well being, not merely the absence of disease or infirmity" (WHO, 1980). This modern approach to health lends itself to oral health as well. The use of patient-based outcome measures in oral health, like oral healthrelated quality of life (OHRQoL), has increased since the 1980's. OHRQoL is a multi-dimensional idea which can be defined as a person's assessment of how functional, psychological, social factors, pain or discomfort affect his/her well being- in the context of oral health. ${ }^{[1]}$

During the last two decades, health-related quality of life $(\mathrm{QoL})$ measurements have been an important issue because of several reasons. First, we need to assess to what extent different diseases and conditions affect individuals' general well-being .Second, it is of utmost importance to assess changes in QoL over time, i.e. before and after different treatments. Third, QoL measures are important to politicians and civil servants as the impact of different diseases and illnesses on both an individual and on a population are crucial with regard to health policies and economics in our society.

A specific branch of QoL is oral health-related quality of life (OHRQoL), and it is important to measure the influence oral health has on QoL. Several OHRQoL instruments have been developed since the 1990s in different countries and cultures, and they are more or less widespread among researchers. The use of these OHRQoL questionnaires is mainly seen in oral epidemiological surveys, and lately in clinical studies. Among the most published and tested OHRQoL instruments is the Oral Health Impact Profile (OHIP). This psychometric test was developed by Slade and Spencer $^{[2]}$ as a 49 -item questionnaire measuring different dimensions of OHRQoL. This questionnaire features functional limitations, physical pain, psychological discomfort, physical disability, psychological disability, social disability and handicap as seven dimensions. Later, Slade published a 14-item version tapping the same dimensions. OHIP-14 has been used both internationally and nationally and is the most used OHRQoL instrument. The vast majority of studies concerning OHRQoL and associated factors such as orofacial pain, functional disability and psychosocial effects show positive relationships, i.e. a higher degree of oral disease and dysfunction imply effects on patients' everyday life situations. According to the concept of oral health-related quality of life (OHRQoL), good oral health is no longer seen as the mere absence of oral disease and dysfunction. The definition of OHRQoL 
includes the absence of negative impacts of oral conditions on social life, and positive sense of dentofacial selfconfidence.

This study aims to determine whether complete dentures improve the quality of life of an edentulous patient, and will also assess the roles of socioeconomic and demographic factors. The study will further assess the association between psychosocial, socioeconomic and demographic factors and patients' level of denture satisfaction.

\section{Methodology}

2.1Study design Patient records at Prosthodontics department, Government Dental College \& Hospital, Ahmedabad were used to identify completely edentulous patients who had received new sets of conventional complete dentures between August to October 2013. A sample of 630 patients was drawn from these patient records using a random numbers method. Addresses of the subjects were obtained from the registration records. 2.2Ethical and legal considerations All patients completed a written, informed consent form .Patients were assured that all information was strictly confidential. The socio-demographic details of the patients were kept separate from the OHIP-EDENT form.

2.3Data collection The OHRQOL was measured using the OHIP-EDENT (Allen and Locker,2002). ${ }^{[3]}$ In addition, some socio-demographic information was also collected like name, age, gender,marital status and employment status .

2.4Data analysesThe answers to the demographic questionnaire were coded and entered into an MS-Excel spreadsheet. The answers to the OHIP-EDENT were entered as per question. The score for each domain was then calculated by multiplying each score by its weighting and adding the scores together to form the domain score (Allen and Locker, 2002). ${ }^{[3]}$ The summary score was obtained by adding all domain scores together .

Results are presented as frequency distributions and mean scores. For the Anova tests, Chi-square tests and Paired T-tests; a p-value <0.05 was considered as statistically significant.The data analyses and re-codings were carried out using the Statistical Package for Social Sciences (SPSS) version 17.

\subsection{Frequency distributions of data collected}

\section{Results}

3.1.1Demography of the sample A final sample of 630 patients was then included in the study. Eighty-one percent $(n=510)$ of the sample was female (Table 1$)$. The age ranged from 34 years to 80 years old with a mean age of 58 years. Fifty-two percent of the sample was $\leq 60$ years of age.

3.1.2Education level Fifty-one percent $(n=320)$ of the sample had secondary (beyond standard 9) education or tertiary education, while $49 \%(n=310)$ had no formal schooling or schooling up to standard 5.

3.1.3Income per month Fifty-six percent $(n=350)$ reported an income below R10000; $14 \%(n=90)$ had an income exceeding R10000 and 30\% $(n=190)$ had no source of income.

3.1.4 Employment status Forty-one percent $(n=260)$ of the sample were pensioners, $31 \%(n=190)$ were employed and $28 \%(\mathrm{n}=180)$ were unemployed.

3.1.5 Dental history Forty-four percent $(n=280)$ had been edentulous for between 16 and 30 years. The mean time span for edentulousness was 25 years. The minimum time a patient was edentulous was 2 months and themaximum period was 59 year.

\subsection{Relationships between demographic variables, socioeconomic variables, dental history and OHIP- EDENT}

3.2.1Age and OHRQOL Patients under the age of 60 years generally reported higher impacts in all domains compared to patients over the age of 60 . The highest scores were recorded in functional limitations (Mean=7.95) and psychologicaldiscomfort (Mean=8). In patients over the age of 60 , the highest impacts were recorded in the domains functional limitations and psychological discomfort. (Fig.1)

3.2.2Gender and OHRQOLFemales recorded higher impacts in all domains except social disability and handicap ( Fig. 2). A significant relationship was found between gender and psychological discomfort $(\mathrm{p}=0.039)$ with the females scoring almost four times higher than males.

3.2.3Education and OHRQOL Patients who had no formal schooling or schooling up to standard 5 reported much lower impacts than patients who had secondary or tertiary education. A significant relationship was found between education and functional limitation $(\mathrm{p}=0.026)$ and physical disability $(\mathrm{p}=0.036)$. The overall summary score was also significantly different $(\mathrm{p}=0.042)$.(Fig.3)

3.2.4Employment status and OHRQOLPensioners consistently reported lower OHRQOL impacts in all the domains except social disability and handicap. The employed patients had the highest scores for the Psychosocial domains and physical disability(Fig. 4). The unemployed patients reported the highest impacts with regard to functional limitation (Mean=8.4) and physical pain (Mean=9.04). A significant relationship was found between social disability and employment. 
3.2.5 Income and OHRQOL Patients who were in a higher income group generally reported more OHRQOL impacts than patients who earned a lower salary (Fig.5).Patients who had no source of income recorded the lowest impacts for social disability (Mean=0.72) and handicap (Mean=0.25). Although differences could be noted no statistically significant relationships werefound.

3.2.6History of edentulousness and OHRQOL Patients who were edentulous for more than 30 years scored fewer impacts in all domains except physical pain, social disability and handicap(Fig. 6). Patients who were edentulous for less than 15 years recorded the highest impact in functional limitation (Mean=7.7), psychological disability (Mean=3.13) and handicap (Mean=1.78). No statistically significant differences were found between the groups.

3.2.7Previous denture experience and OHRQOL Patients who had no previous denture experience generally scored higher than those patients who had more than five years previous denture experience ( Fig. 7). Significant relationships were found between social disability $(\mathrm{p}=0.01)$ and handicap $(\mathrm{p}=0.01)$ and previous denture experience.

3.2.8Denture satisfaction and OHRQOL Maxillary denture:Patients who were not satisfied with their new dentures scored significantly higher in all domains (Fig. 8). Physical pain was the domain most affected followed by functional limitations. Significant relationships were recorded in all domains. Thus, maxillary denture satisfaction is a predictor of OHRQOL.

Mandibular denture: Patients who were satisfied with their mandibular dentures reported fewer impacts on their OHRQOL ( Fig. 9). Significant relationships were recorded in all domains.

IV. Figures \& Tables

\begin{tabular}{|c|l|l|l|}
\hline \multicolumn{2}{|c|}{ Demographic Frequency } & \multicolumn{1}{|c|}{ (n) } & \multicolumn{1}{c|}{$\%$} \\
\hline \multirow{5}{*}{ Gender } & Male & 120 & 19 \\
\cline { 2 - 4 } & Female & 510 & 81 \\
\hline \multirow{3}{*}{ Ege Group } & $<60$ years & 330 & 52 \\
\cline { 2 - 4 } & $>60$ years & 300 & 48 \\
\hline \multirow{3}{*}{ Employment } & Secondary or Tertiary & 320 & 51 \\
\cline { 2 - 4 } & Primary & 310 & 49 \\
\cline { 2 - 4 } & Employed & 190 & 28 \\
\cline { 2 - 4 } & Unemployed & 180 & 41 \\
\cline { 2 - 4 } & Pensioners & 260 & 21 \\
\hline
\end{tabular}

Table 1: Frequency distribution of Demographic data

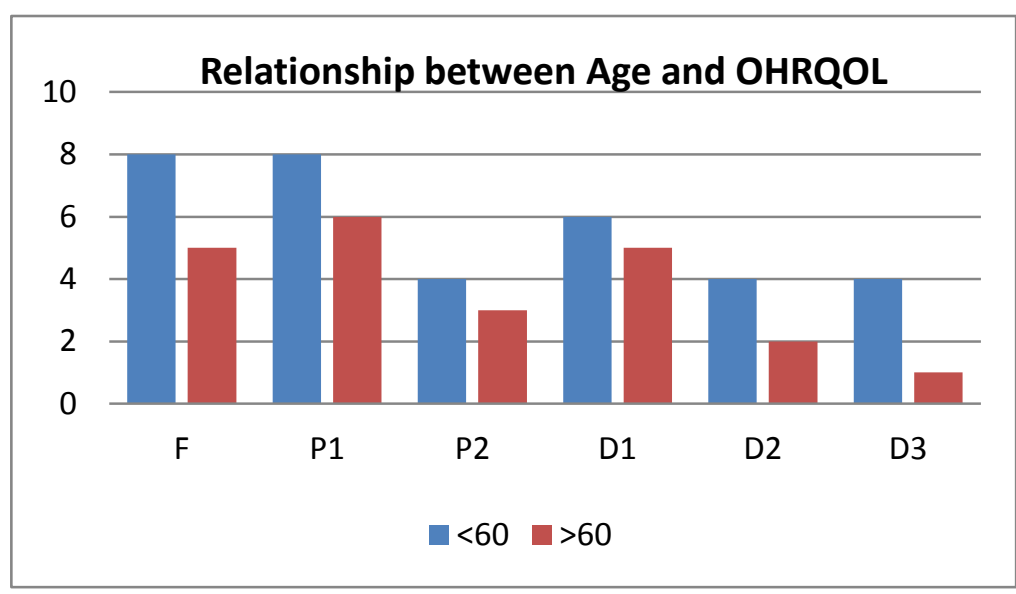

\begin{tabular}{|c|c|}
\hline Variable & P-value \\
\hline F & 0.07 \\
\hline P1 & 0.37 \\
\hline P2 & 0.09 \\
\hline D1 & 0.13 \\
\hline D2 & 0.02 \\
\hline D3 & 0.21 \\
\hline
\end{tabular}

Figure 1: Relationship between Age and OHRQOL 
$\mathrm{F}=$ functional limitation, $\mathrm{P} 1=$ physical pain, $\mathrm{P} 2=$ psychological discomfort, $\mathrm{D} 1=$ physical disability, $\mathrm{D} 2=$ psychological disability, D3= social disability and $\mathrm{H}=$ handicap.

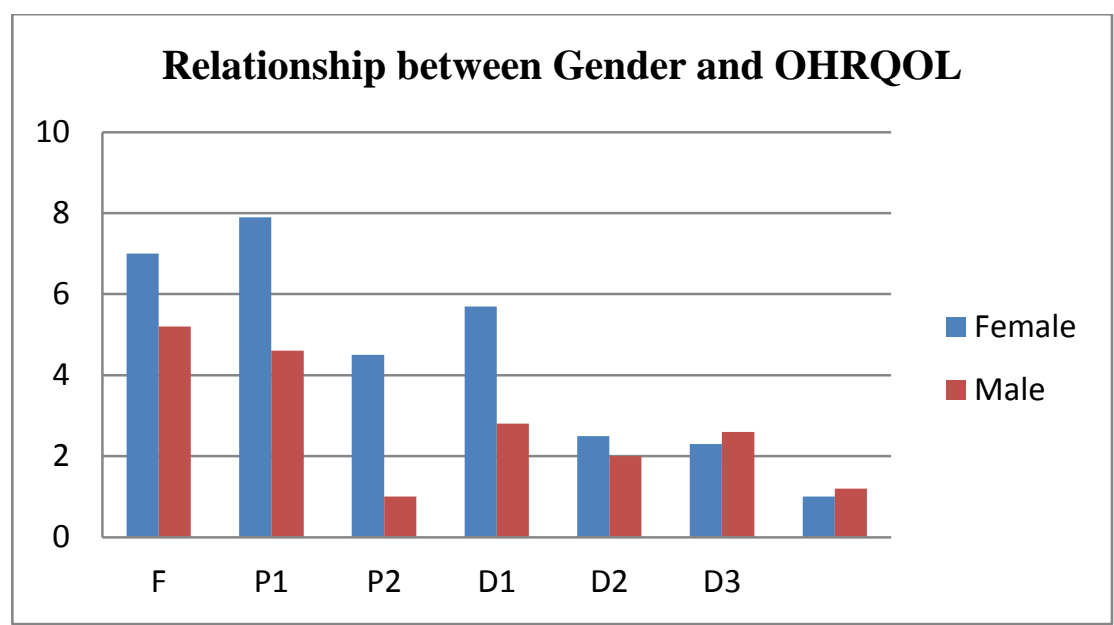

\begin{tabular}{|c|c|}
\hline Variable & P-value \\
\hline $\mathrm{F}$ & 0.28 \\
\hline $\mathrm{P} 1$ & 0.13 \\
\hline $\mathrm{P} 2$ & 0.04 \\
\hline $\mathrm{D} 1$ & 0.19 \\
\hline $\mathrm{D} 2$ & 0.58 \\
\hline $\mathrm{D} 3$ & 0.78 \\
\hline $\mathrm{H}$ & 0.79 \\
\hline
\end{tabular}

Figure 2: Relationship between Gender \& OHRQOL

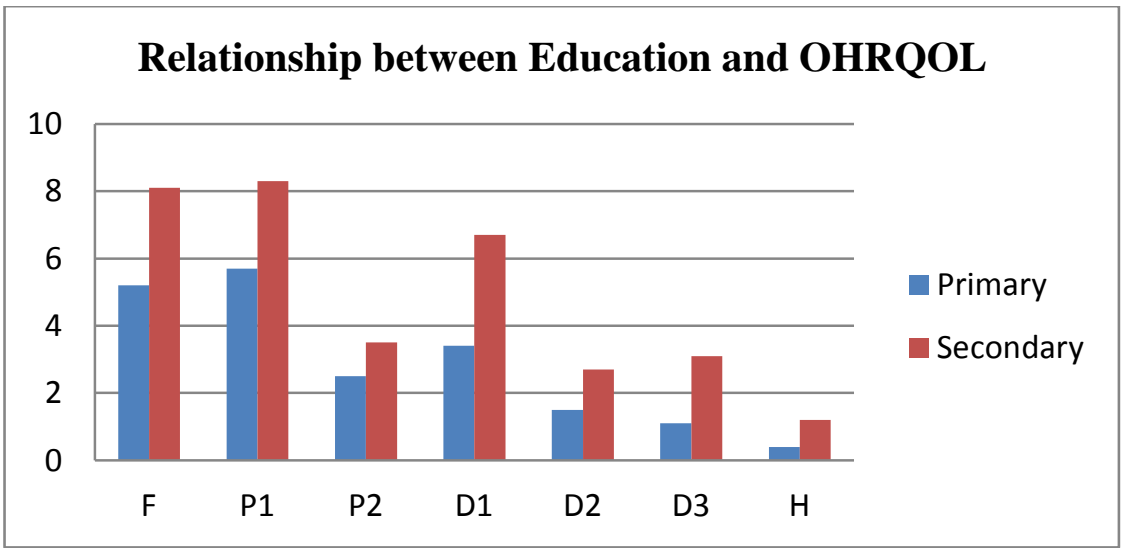

\begin{tabular}{|c|c|}
\hline Variable & P-value \\
\hline F & 0.03 \\
\hline P1 & 0.96 \\
\hline P2 & 0.36 \\
\hline D1 & 0.04 \\
\hline D2 & 0.19 \\
\hline D3 & 0.13 \\
\hline H & 0.08 \\
\hline
\end{tabular}

Figure 3 : Relationship between education \&OHRQOL 


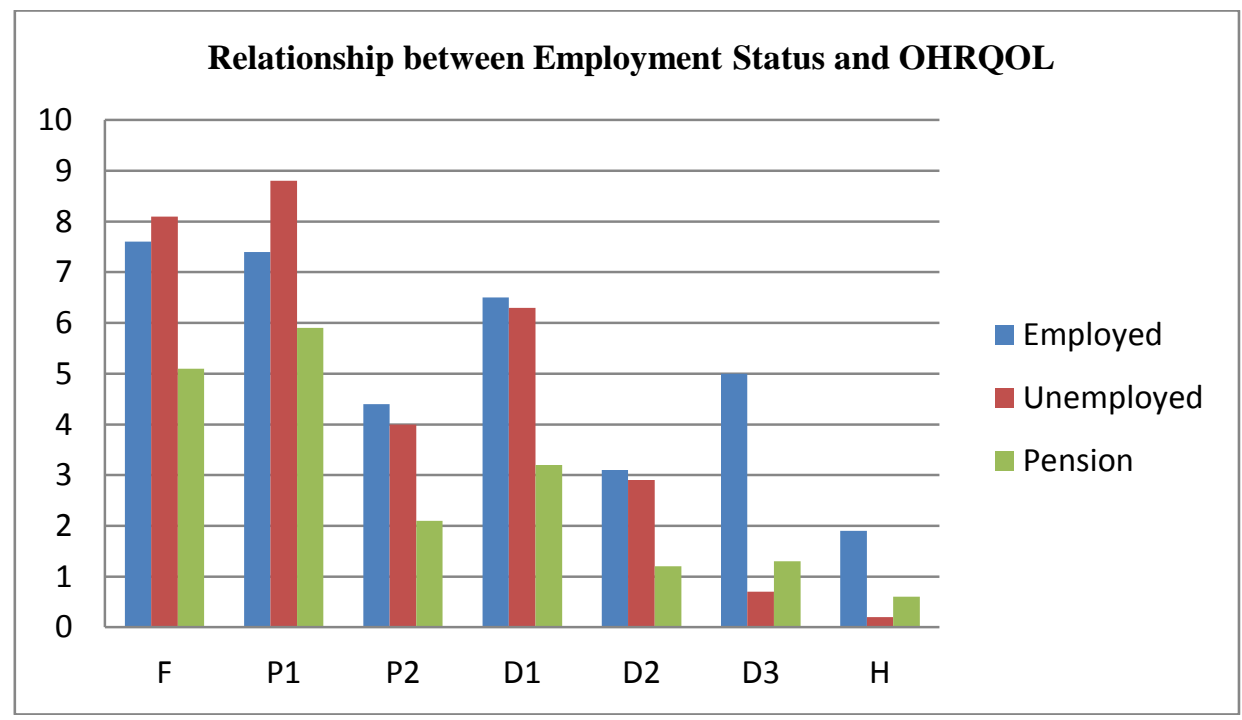

\begin{tabular}{|c|c|}
\hline Variable & P-value \\
\hline F & 0.14 \\
\hline P1 & 0.30 \\
\hline P2 & 0.24 \\
\hline D1 & 0.14 \\
\hline D2 & 0.14 \\
\hline D3 & 0.05 \\
\hline H & 0.13 \\
\hline
\end{tabular}

Figure 4: Relationship between employment status \& OHRQOL

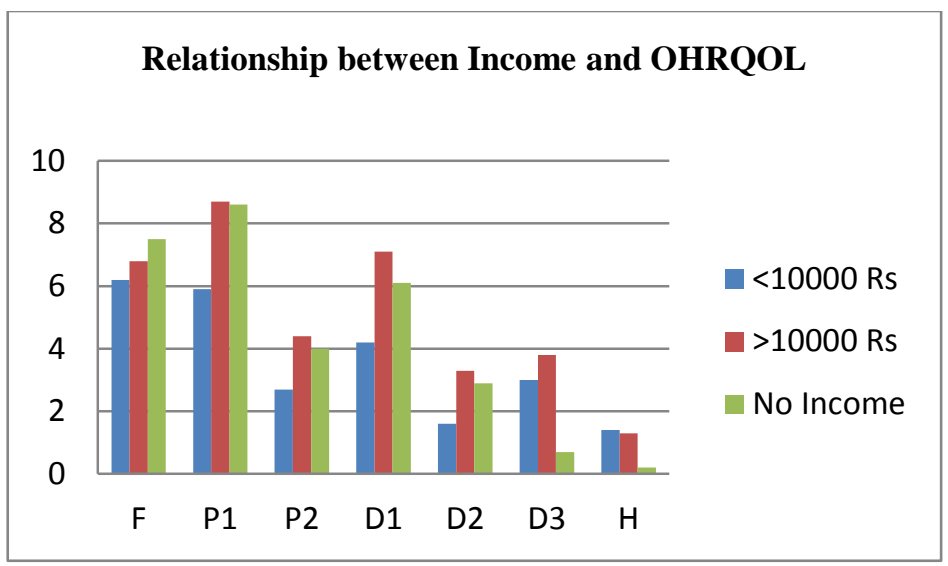

\begin{tabular}{|c|c|}
\hline Variable & P-value \\
\hline F & 0.58 \\
\hline P1 & 0.25 \\
\hline P2 & 0.58 \\
\hline D1 & 0.29 \\
\hline D2 & 0.41 \\
\hline D3 & 0.29 \\
\hline H & 0.36 \\
\hline
\end{tabular}

Figure 5: Relationship status between Income \& OHRQOL 


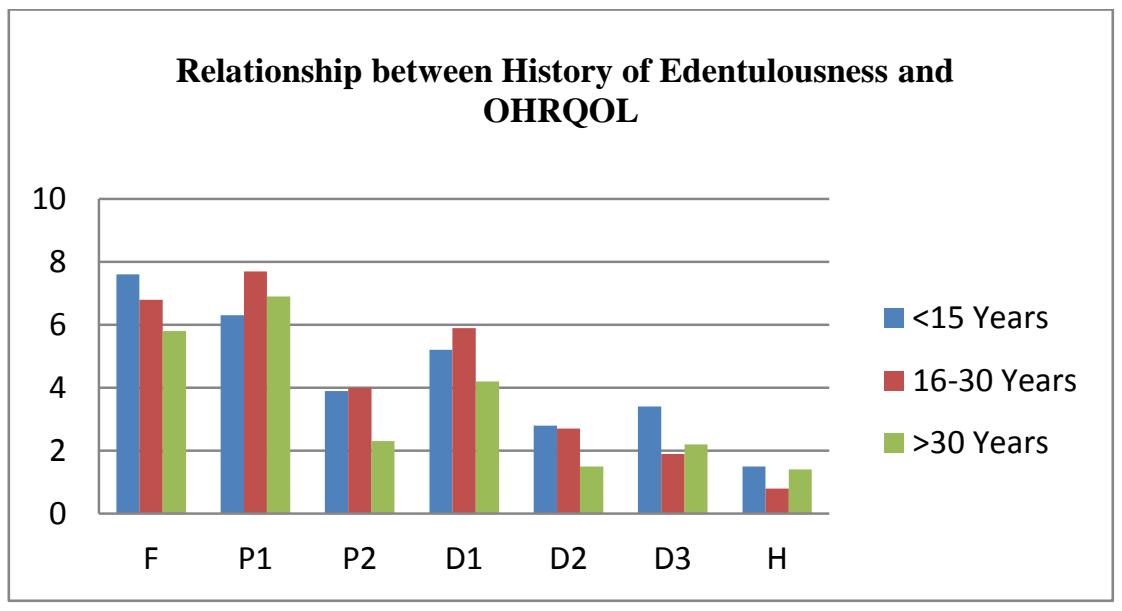

\begin{tabular}{|c|c|}
\hline Variable & P-value \\
\hline $\mathrm{F}$ & 0.64 \\
\hline $\mathrm{P} 1$ & 0.81 \\
\hline $\mathrm{P} 2$ & 0.50 \\
\hline $\mathrm{D} 1$ & 0.62 \\
\hline $\mathrm{D} 2$ & 0.53 \\
\hline $\mathrm{D} 3$ & 0.63 \\
\hline $\mathrm{H}$ & 0.50 \\
\hline
\end{tabular}

Figure 6: Relationship between History of edentulousness \& OHRQOL

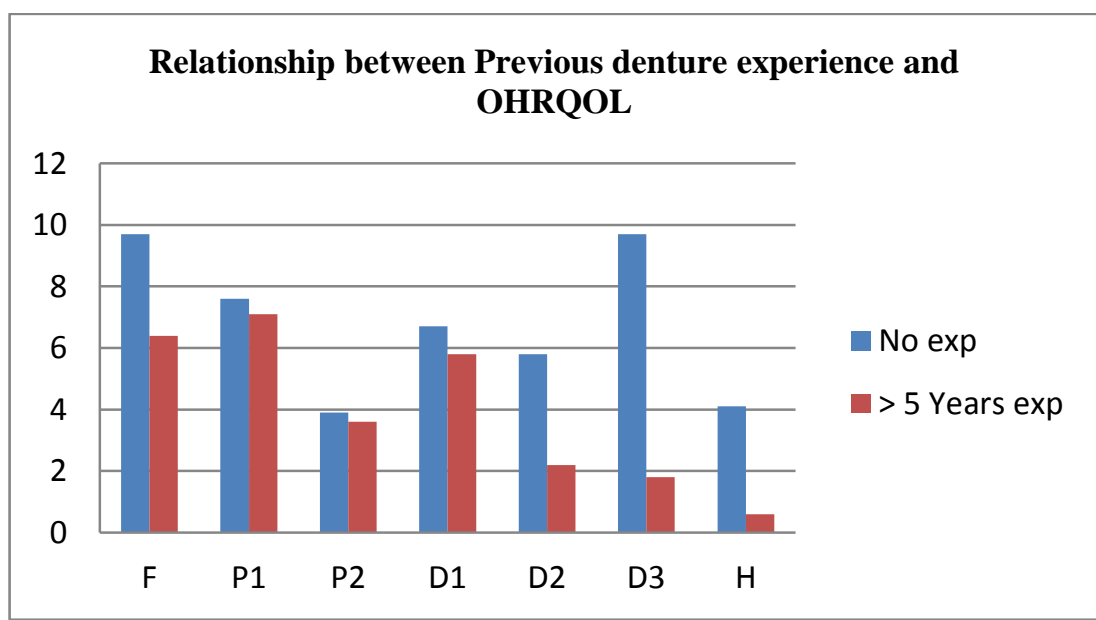

\begin{tabular}{|c|c|}
\hline Variable & P-value \\
\hline F & 0.25 \\
\hline P1 & 0.76 \\
\hline P2 & 0.77 \\
\hline D1 & 0.54 \\
\hline D2 & 0.09 \\
\hline D3 & 0.001 \\
\hline H & 0.001 \\
\hline
\end{tabular}

Figure 7: Relationshoip between previous denture experience\& OHRQOL 


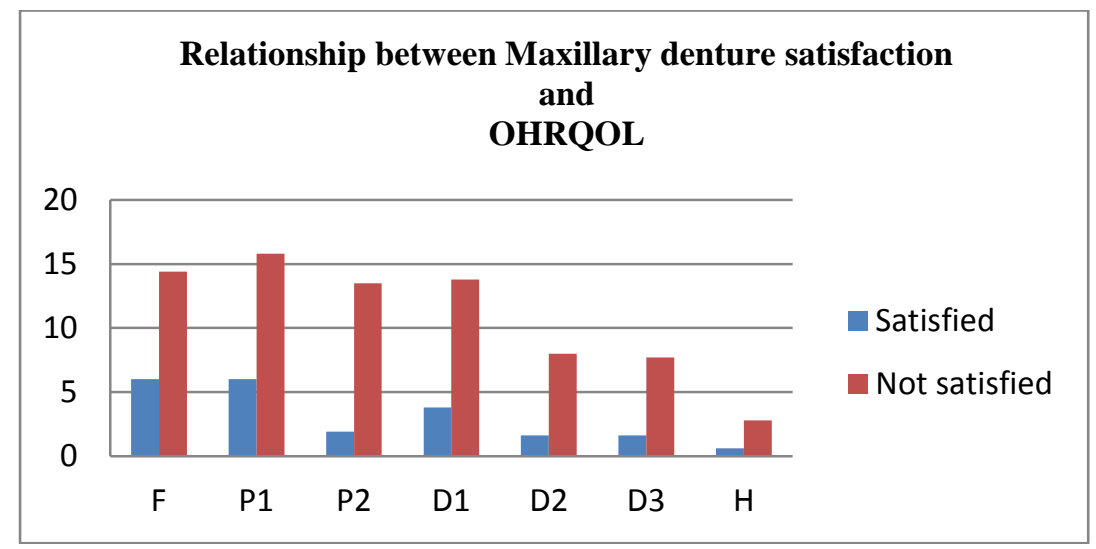

\begin{tabular}{|c|c|}
\hline Variable & P-value \\
\hline $\mathrm{F}$ & $<0.001$ \\
\hline $\mathrm{P} 1$ & $<0.001$ \\
\hline $\mathrm{P} 2$ & $<0.001$ \\
\hline $\mathrm{D} 1$ & $<0.001$ \\
\hline $\mathrm{D} 2$ & $<0.001$ \\
\hline $\mathrm{D} 3$ & 0.01 \\
\hline $\mathrm{H}$ & .03 \\
\hline
\end{tabular}

Figure 8 : Relationship between maxillary denture satisfaction \& OHRQOL

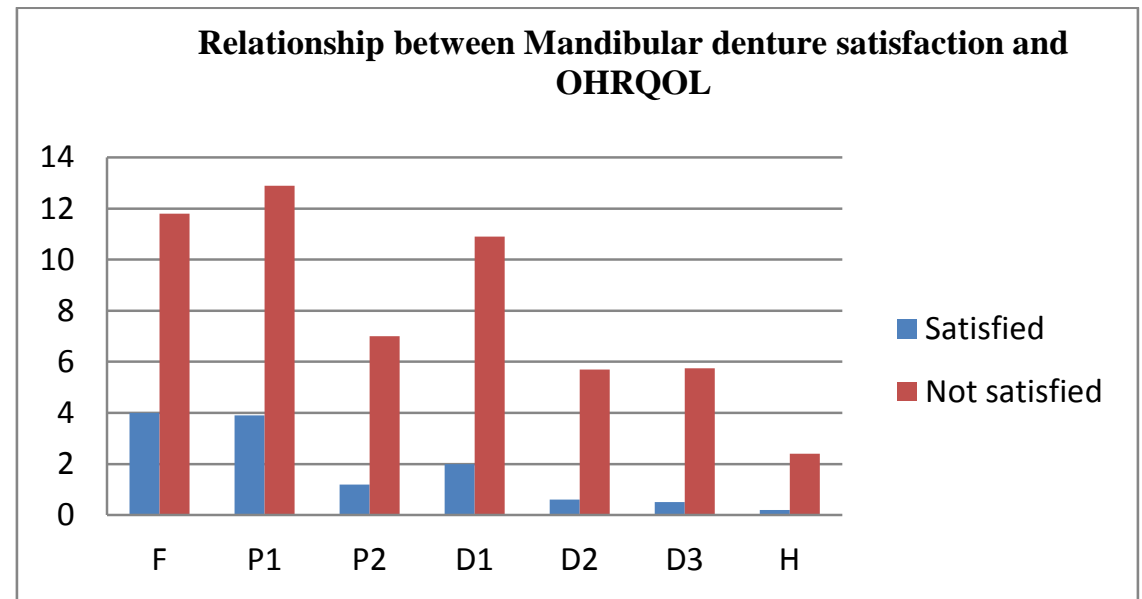

\begin{tabular}{|c|c|}
\hline Variable & P-value \\
\hline F & $<0.001$ \\
\hline P1 & $<0.001$ \\
\hline P2 & $<0.001$ \\
\hline D1 & $<0.001$ \\
\hline D2 & $<0.001$ \\
\hline D3 & $<0.001$ \\
\hline H & $<0.001$ \\
\hline
\end{tabular}

Figure 9 : Relationship between mandibular denture satisfaction \& OHRQOL

\section{Discussion}

This study provides data about impaired OHRQoL in patients seeking prosthodontic treatment and receiving complete dentures in Gujarat. It was found that these patients have a considerably impaired level of OHRQoL prior to treatment. A statistically significant improvement was observed in the psychological discomfort, psychological disability, social disability and handicap domains. Although most patients were satisfied with their maxillary dentures, the mandibular denture resulted in dissatisfaction. 
The mean age of the sample was 58 years and about half of the sample was older than 61 years. The results of this study may be skewed because of the uneven gender distribution. However, the findings 85 of the present study support the trend in previous local studies (Naude etal, 1994; Naidoo et al, 2001) ${ }^{[4,5]}$ that females are more likely to be edentulous than males.The average patient in this sample was edentulous for 25 years (meanhistory of edentulousness). This implies that the patient becameedentulous at a mean age of 34 years. This finding is in accordance with previous studies (Louw and Moola, 1979; Naude et al, 1994; Naidoo et al,2001 $)^{[6,4,5]}$ that edentulousness increases with age. This could be because the older patients are more likely to suffer from medical conditions as well and that edentulousness is viewed as a more hassle-free condition. Also, these patients may have been part of a generation who did not place much confidence in restorative dentistry or understand the advantages of periodontal treatment. As a result, older patients experienced higher rates of tooth loss. Tooth loss is one of the severe compromises of dental function. It is the dental equivalent of mortality. Tooth loss reflects the attitude of patients,service providers, availability and accessibility of care and the prevailing mindset about dental treatment.

The results of this study highlight the need for more effective health promotion and prevention programmes. However, the results of this study should provide motivation for the creation and sustainability of outreach programmes in the rural areas or areas where access to oral health care is a problem.

$56 \%$ subjects were with an income below R 10000 and $30 \%$ without a source of income. Only less than a third $(31 \%)$ were employed. More than half of the sample had a low income and this could be explained by the fact that almost half of the sample was pensioners. Half the sample had no formal schooling. Edentulous patients are more likely to come from lower socio-economic background as reflected in the results concerning the demographic data, especially in the low levels of income and education (Heydecke et al, 2004). ${ }^{[7]}$

The dental hospital also provides an affordable alternative for oral health treatment and so, it is not surprising that the majority of the patients are from the lower income group who could not afford private treatment. It would be expected that the majority of people who use the public healthcare services could not afford treatment in the private healthcare setting.

Generally, all the patients were satisfied with the maxillary denture received during their treatment. A higher rate of dissatisfaction was recorded for the mandibular denture $(36 \%)$ than the maxillary denture (10\%). It is a clinically known fact that the lower denture is more problematic and this has been verified by Carlsson et al (1967) ${ }^{[8]}$ These findings are higher than the 20\% dissatisfaction rate found in the NOHS of 1989 (Naude et al, $1994)^{[4]}$ Patients who have worn dentures previously are able to relearn or reinforce the neuromuscular control required to stabilise a denture more quickly than a patient who has no previous experience (Weinstein et al, 1988). ${ }^{[9]}$ Also, patients with previous experience may have more realistic aesthetic and psychosocial expectations.However, the findings of this study supported Van Waas (1990a, 1990b) ${ }^{[10,11]}$ who found no correlation between previous denture experience and denture satisfaction.

Age and gender was found not to have an influence on denture satisfaction. This finding is in agreement with Baer et al (1992) ${ }^{[12]}$, that gender may only represent a minor to moderate influence on satisfaction with complete dentures. In studies conducted by Mersel et al $(1995)^{[13]}$ and Weinstein et al (1988), ${ }^{[9]}$ age was found not to be a predictor of denture success.

Denture satisfaction is a predictor of OHRQOL. Significant relationships were found between maxillary and mandibular denture satisfaction and all domains of OHRQOL. These results were in correlation with Yoshida et al $(2001)^{[14]}$, who agreed that patients who were satisfied with their dentures were also satisfied with their quality of life. In this study, it was found that patients who were dissatisfied with their maxillary denture scored higher impacts in functional limitations (Mean=14.8) and physical pain (Mean=16.5). This is in contrast to Berg (1988) ${ }^{[15]}$ who found that one year post-insertion, patients still experiencedmore pain related to the mandibular denture. With regards to function,Garrett et al (1996) ${ }^{[16]}$ found a high correlation between perceptions of chewing ability, eating enjoyment, food choices and particles underdentures.

More than two thirds $(68 \%)$ of the sample experienced great difficulty eating with their previous dentures and only $42 \%$ experienced pain in their mouth in the last month. Patients recorded higher impacts related to functional limitations. This could be due to ill-fitting dentures, inadequate retention and the resulting discomfort experienced by edentulous patients (Heydecke et al, 2004). ${ }^{[7]}$ This suggests that although they experienced great difficulty with eating, patients persevered because it was not painful. Most edentulous patients feel helpless and believe that they have to accept denture problems as part of wearing a prosthesis (Awad et al,2003a). ${ }^{[17]}$ A substantial proportion of edentulous patients with complete dentures reported an impaired OHRQOL. Almost half of the patients (48\%) were worried by dental problems and upset about problems with their dentures. Almost a third (30\%) of patients admitted to finding life less satisfying because of problems with their dentures. The most prevalent impacts were recorded in the functional limitation domain followed by psychological discomfort and physical pain was ranked third. It is difficult to compare the results of this study because of the difference in study design, age and sample size. However, Heydecke et al (2004) ${ }^{[7]}$ found the most prevalent impacts to be physical pain, functional limitation and physical disability. Ill-fitting dentures may 
adversely affect the appearance of the patient hence the high scores in the psychosocial domains. It has been suggested that the longer dentures are worn, the better they are tolerated, despite a poor fit (Rise and Heloe, 1978) ${ }^{[18]}$ Denture age and quality of the patients' existing denture was not taken into account and was a weakness of the study. However, researchers have stated that the clinical evaluation of the quality of the dentures is unreliable due to the lack of acceptable and reliable criteria (Berg, 1993; Weinstein et al, 1988; Carlsson et al, 1967). ${ }^{[19,9,8]}$ Also, there have been conflicting results regarding the influence of denture quality on patient satisfaction (Fenlon and Sherriff, 2004; Wolff et al, 2003; Yoshizumi, 1964; Carlsson et al, 1967). ${ }^{[20,21,22,8]}$

\section{Conclusion}

The findings of this study could also serve as motivation for a more vigorous national plan with regards to oral health. The high prevalence of edentulism clearly suggests that the levels of tooth loss are not decreasing. The high rate of decay and periodontal disease in Gujarat also contributes to this problem. As a result, we need to make oral health a more affordable and attractive alternative to extracting teeth and replacing them with complete dentures. The public needs to be made aware of the importance of oral health to their quality of life. In Gujarat, the Dental Hospitals should take up the challenge in changing the perceptions of the public regarding oral health.Currently, Public Health Services place a low priority on the provision of dentures. Complete denture construction is viewed as a resource intensive service and cannot be justified as a priority. Other demands such as housing, education and primary health care are given preference. The results of this study and future research could be used to motivate for more appropriate resource allocation. At the moment few dental clinics provide a denture service, with the result that most patients are referred to the teaching hospitals for treatment. The shortage of personnel in the academic hospitals means that lengthy waiting lists are the norm. The Health Services should explore the possibility of creating more service rendering posts at the community dental clinics and providing them with a budget to comprehensively treat patients.

\section{References}

[1]. Strassburger C, Heydecke G, Kerschbaum T. Influence of prosthetic and implant therapy on satisfaction and quality of life: A systematic review. Int J Prosthodont 2004;17:83-93.

[2]. Slade GD, Spencer A. Development and evaluation of the Oral Health Impact Profile. Community Dent Health 1994;11:3-11.

[3]. Allen PF, Locker D. A modified short version of the Oral Health Impact Profile for assessing health-related quality of life in edentulous adults. Int J Prosthodont 2002;15:446-50.

[4]. Naude DA, Van Rooy HK, Faber HS, Barrie RB. Complete upper and lower dentures: Results from the sociological questionnaire of the National Oral Health Survey. National Oral Health Survey South Africa 1989. In: Report of the first National Oral Health Survey of South Africa, pp 102-8. Department of Health, 1994.

[5]. Naidoo S, Chikte UM, Moola H, Steyn K. Perceptions of oral health: The South African Demographic and Oral Health Survey (DOHS) of 1998. SADJ 2001;56:505-10.

[6]. Louw NP, Moola MH. The dental needs and demands of the Cape Coloured people in the Cape Peninsula. J Dent Assoc S Afri 1979; $34: 715-8$.

[7]. Heydecke G, Tedesco LA, Kowalski C, Inglehart MR. Complete dentures and oral health-related quality of life-do coping styles matter? Community Dent Oral Epidemiol 2004;32:297-306.

[8]. Carlsson GE, Otterland A, Wennstrom A. Patient factors in appreciation of complete dentures. J Prosthet Dent 1967;17:322-8.

[9]. Weinstein M, Schuchman J, Lieberman J. Age and denture experience as determinants in patient denture satisfaction. J Prosthet Dent 1988;59:327-9.

[10]. Van Waas M. The influence of clinical variables on patients' satisfaction with complete dentures. J Prosthet Dent 1990a;63:307-10.

[11]. Van Waas M. Determinants of dissatisfaction with dentures: A multiple regression analysis. J Prosthet Dent 1990b;64:569-72.

[12]. Baer ML, Elias SA, Reynolds MA. The use of psychological measures in predicting patient satisfaction with complete dentures. Int J Prosthodont 1992;5:221-6.

[13]. Mersel A, Babayof I, Berkey D, Mann J. Variables affecting denture satisfaction in Israeli elderly: a one-year follow-up. Gerodontology 1995;12:89-94.

[14]. Yoshida M, Sato Y, Akagawa Y, Hiasa K. Correlation between quality of life and denture satisfaction in elderly complete denture wearers. Int JProsthodont 2001;14:77-80.

[15]. Berg E. A 2-year follow-up study of patient satisfaction with new complete dentures. J Dent . 1988;16:160-5.

[16]. Garrett NR, Kapur KK, Perez P. Effects of improvements of poorly fitting dentures and new dentures on patient satisfaction. J Prosthet Dent 1996;76:403-13.

[17]. Awad MA, Lund JP, Dufresene E, Feine JS. Comparing the efficacy of mandibular implant-retained overdentures and conventional dentures among middle-aged edentulous patients: satisfaction and functional assessment. Int J Prosthodont 2003a;16:117-22.

[18]. Rise J, Heloe LA. Oral conditions and treatment need in an elderly population in Northern Norway. Community Dent Oral Epidemiol 1978;6:6-11.

[19]. Berg E. Acceptance of full dentures. Int Dent J. 1993;43:299-306.

[20]. Fenlon MR, Sherriff M. Investigation of new complete denture quality and patients' satisfaction with and use of dentures after two years. J Dent 2004;32:327-33.

[21]. Wolff A, Gadre A, Begleiter A, Moskana D, Cardash H. Correlation between patient satisfaction with complete dentures and denture quality, oral condition and flow rate of submandibular/sublingual salivary glands. Int J Prosthodont 2003;16:45-8.

[22]. Yoshizumi DT. An evaluation of factors pertinent to the success of complete denture service. J Prosthet Dent 1964;14:866-78. 